This is the final peer-reviewed accepted manuscript of:

Locatello L, Bertotto D, Cerri R, et al. Sperm quality in wild-caught and farmed males of the European eel (Anguilla anguilla). Anim Reprod Sci. 2018;198:167-176.

The final published version is available online at: doi:10.1016/j.anireprosci.2018.09.016

Rights / License:

The terms and conditions for the reuse of this version of the manuscript are specified in the publishing policy. For all terms of use and more information see the publisher's website.

This item was downloaded from IRIS Università di Bologna (https://cris.unibo.it/)

When citing, please refer to the published version. 


\section{Sperm quality in wild caught and farmed males of the European eel (Anguilla}

2 anguilla).

3 Locatello L. ${ }^{\mathrm{a},{ }^{*}}$, Bertotto D. ${ }^{\mathrm{b},}$, Cerri R. ${ }^{\mathrm{b}}$, Parmeggiani A. ${ }^{\mathrm{c}}$, Govoni N. ${ }^{\text {, }}$, Trocino A. ${ }^{\mathrm{b}}$, Xiccato G. ${ }^{\mathrm{d}}$,

4 Mordenti O. ${ }^{\mathrm{c}}$

5

6 a Department of Biology, University of Padova, via U. Bassi 58/b, 35121 Padova, Italy

7 b Department of Comparative Biomedicine and Food Science (BCA), University of Padova, Viale

8 dell’Università 16, I-35020 Legnaro, Padova, Italy

$9{ }^{c}$ Department of Veterinary Medical Sciences, University of Bologna, Viale Vespucci 2, 47042

10 Cesenatico, Forlì-Cesena, Italy

11 d Department of Agronomy Food Natural Resources Animal and Environment (DAFNAE),

12 University of Padova, Viale dell’Università 16, I-35020 Legnaro, Padova, Italy

$14 *$ Equal contribution of the first and second author

corresponding author: Daniela Bertotto

daniela.bertotto@unipd.it

Department of Comparative Biomedicine and Food Science (BCA), University of Padova, Viale dell’Università 16, I-35020 Legnaro, Padova, Italy

E-mail addresses: lisa.locatello@unipd.it (L. Locatello), daniela.bertotto@unipd.it (D. Bertotto), nadia.govoni@unibo.it (N. Govoni), angela.trocino@unipd.it(A. Trocino),

Declarations of interest: none 


\section{ABSTRACT}

Sperm density and performance of wild and farmed male European eels were evaluated to investigate the effect of maintenance in captivity on ejaculate quality. Hormonal stimulation (with human chorionic gonadotropin) lasted for 17 weeks. Different origins of the male European eels partially influenced the quality of the ejaculates. Indeed, wild animals (i.e., collected at a natural site) had greater sperm longevity during the hormonal stimulation, whereas there was no significant effect of the origin on sperm density, spermatocrit, the percentage of motile sperm, and plasma testosterone concentrations. The different origins of the males also affected fatty acid sperm content, with greater unsaturated fatty acid and omega-6 concentrations in wild eels and lesser concentrations of saturated fatty acids and omega-3 fatty acids in farmed eels. Regarding sperm quality of European eels, this is the first study that takes into account the effect of different origins of stimulated males (wild-caught compared with farmed) on sperm quality, and these findings may help to improve the production of high-quality gametes in this endangered species.

Keywords: European eel; Captivity; Sperm; ejaculate Quality; Fatty acids

\section{Introduction}

The European eel (Anguilla anguilla) is a catadromous teleost fish that spends most of its life in freshwater of lakes and rivers until the spawning migration from the European coastal waters to the Sargasso Sea. In the last century, the European eel population has constantly decreased due to predators and anthropogenic pressure (e.g., migration barriers, hydropower turbine-induced mortality, natural habitat degradation, and overfishing; Bevacqua et al., 2015). Eel fisheries and farming activities in Europe totally rely on wild stocks, which dramatically decreased in recent decades (Dekker et al., 2003; Stone, 2003). For these reasons, the European eel is now considered a 'critically endangered' species (IUCN, 2015), and the development of techniques for reproduction in captivity is becoming necessary. 
During adaptation to the saline environment, eels have with morphological changes as the skin pigmentation turns from yellow to silver and with complex physiological changes that help with adaptation for the long migration period. During silvering, gonadal development is inhibited by complex hormonal control, and it is next released to initiate the reproductive process, but the timing and mechanisms responsible for the cessation of inhibition are still unclear (Tomkiewicz et al., 2011). In captivity, gametogenesis in the European eel can be induced only through hormonal stimulation, and injections of human chorionic gonadotropin (hCG) into males and of a fish pituitary extract into females are commonly used to induce sexual maturation in the European eel, as well as in various other eel species (Tanaka et al., 2001). In addition, injection of 17 $\alpha, 20 \beta-$ dihydroxy-4-pregnen-3-one (DHP) for final female maturation and induction of ovulations results in increased fertility and hatching rates (A. japonica: Ohta et al., 1996). Fertilized eggs and production of viable embryos and larvae are now feasible (Palstra et al. 2005; Butts et al., 2016; Sørensen et al., 2016).

Monitoring of gamete quality is a key issue for efficient artificial reproduction strategies. Indeed, the quality of gametes reliably predicts a gamete's capacity to successfully fertilise or be fertilised and to produce viable offspring (Migaud et al., 2013). In the European eel, there has been reliable spawning techniques and protocols developed (Mordenti et al., 2013), thus, the evaluation of gamete quality is becoming a key step to optimise artificial breeding strategies. Traditionally, the fish farming industry has been more focused on the monitoring of egg and larvae quality, rather than on milt, even though milt quality may also affect the production of healthy offspring (Rurangwa et al., 2004). Nonetheless, recent studies on aquaculture increased the focus on sperm quality (Migaud et al., 2013), and studies on European-eel reproduction are not an exception (Peñaranda et al., 2010; Gallego et al., 2012). Because the progression of gonadal development has not been ascertained in European eels, increasing research interest is focused on assisted reproduction in captivity. Male European eels can be difficult to find (and capture) in nature and 
need to determine whether short-term (wild caught) and/or long-term (farmed) captive rearing is affecting reproductive performance of male European eels. Hence, the present study was conducted to compare i) sperm density and performance, ii) sperm fatty acid content, and iii) testosterone profiles between wild-caught and farmed male European eels after hormonal stimulation.

\section{Materials and methods}

\subsection{Fish sampling and maintenance}

Thirteen male adult silver eels (Durif et al., 2005) were used. Six individuals (wild) were collected at a natural site near the sluices of the North Adriatic Sea (Val Noghera, Lagoon of Grado, Italy) using a traditional 'lavoriero' (downstream trap). Seven individuals (farmed) were selected on a controlled fish farm (Succi Fish Farming, Goro, Italy). Due to the different origins, the animals of the two groups were subjected to a different feeding regimen until sampling: wild eels were given natural feed, usually made up of Polychaeta, insects, crustaceans, and small fish (see Costa-Dias \& Lobón-Cerviá, 2008, Mordenti et al., 2016), whereas farmed eels were fed with an extruded feed for eels (ALTERNA EEL, Skretting; composition: fish meal, fish oil, wheat red dog, wheat gluten, blood meal from poultry, a soya bean protein concentrate, swine haemoglobin, and whey powder).

Both wild and farmed eels were moved to the facilities of the Department of Veterinary Medical Sciences (Cesenatico, Italy). All the animals were weighed, individually marked by inserting fish-tags (FLOY TAG Mod Floy T-Bar Anchor), and maintained in two separate $700 \mathrm{~L}$ tanks. Wild and farmed males did not differ in the baseline average weight (mean \pm st.dev.: wild, 112.2 $\mathrm{g} \pm 25.8$; farmed, $90.9 \mathrm{~g} \pm 16.8 ; t$ test, $\mathrm{t}=1.79$, degrees of freedom $[\mathrm{df}]=11, \mathrm{p}=0.101)$. All eels were gradually acclimated during the first 7 days to reach the standard experimental conditions: temperature of $15 \pm 0.5^{\circ} \mathrm{C}$, salinity of $32 \%, \mathrm{pH} 7.8$, and dissolved oxygen $9 \mathrm{ppm}$. The maintenance water was collected directly from the sea, through a hydraulic pump drawing offshore, and was properly decanted before use. During the experimental period, the eels were maintained in darkness and without feeding according to previously published protocols (Dollerup and Graver, 1985). The 
animal sampling and manipulation procedures were approved by the Ethical Committee of the

Bologna University ( ${ }^{\circ}$ 19/69/12).

\subsection{Hormonal stimulation}

To induce the ejaculate production, the male eels received a weekly intramuscular injection of $1.0 \mathrm{IU} / \mathrm{g}$ hCG (Corulon, $5000 \mathrm{UI}$, Intervet, Segrate, Milan, Italy) using the previously published protocol (Mordenti et al., 2013). Prior to injection, all the animals were anaesthetised with phenoxyethanol (400 ppm).

The hormonal stimulation started in March 2014 and lasted for 17 weeks (experimental timeline in Fig. 1). Most of the male eels started to produce high quality ejaculates starting from the $11^{\text {th }}$ week, but all the males produce high quality ejaculates starting from the $13^{\text {th }}$ week; thus, sperm analyses lasted from the $13^{\text {th }}$ to $17^{\text {th }}$ week (Fig. 1).

\subsection{Ejaculate sampling}

Ejaculates were collected 24 hours after the hormone injection (Pérez et al., 2000) with the exception of the $13^{\text {th }}$ week when milt samples of nine males (five wild, four farmed) were sampled 48 hours after the hormone injection. The time interval between the injection and ejaculate analyses (24 or 48 hours) was, then, included as a factor in the data analyses (see 2.9. Statistical analyses).

Each eel was anaesthetised (phenoxyethanol, $400 \mathrm{ppm}$ ), placed in a dry cloth, and the ejaculate was collected by a delicate pressure on the abdomen after accurate cleaning the urogenital area to avoid any contamination by urine or faeces. The ejaculate was collected directly into a 15 $\mathrm{mL}$ vial with the help of a plastic catheter. To prevent any excessive stress, the males were not stripped to the extent all semen was removed and a maximum amount of $2 \mathrm{~mL}$ of an ejaculate was collected. The samples were maintained at 3 to $5{ }^{\circ} \mathrm{C}$ until sperm quality analyses, which were performed within 1 hour after collection (Pérez et al., 2000). 


\subsection{Sperm concentration}

Sperm concentration was measured by both spermatocrit (i.e., the ratio of packed sperm to the total volume of milt $\times 100)$ and sperm density by means of a Neubauer Improved haemocytometer (sperm number per microliter of an ejaculate), and the results of the two methods were then compared according to previously published studies (Sørensen et al., 2013).

To measure the spermatocrit, a subsample of the ejaculate was gently mixed by vortexing and was drawn into a microhaematocrit tube (75 mm long; $1.1-1.2 \mathrm{~mm}$ diameter), then sealed with wax. Two tubes for each male were collected and centrifuged for 5 minutes at $13000 \times g$. The proportion of sperm was measured on a micrometric scale. The mean of the two measurements per male was used for statistical analyses. Repeatability of the measurement (i.e., the statistical measure of the consistency of repeated measurements, calculated according to Becker, 1984) - determined for each sampling week - was always greater than 0.993 .

For sperm cell counting, an ejaculate was diluted via a two-step procedure by first diluting the sample 1:5 and then at 1:200, to attain a final dilution of 1:1000. Dilution was conducted with an inactivating extender $\left(3.5 \mathrm{~g} / 1 \mathrm{NaCl}, 0.11 \mathrm{~g} / 1 \mathrm{KCl}, 0.39 \mathrm{~g} / 1 \mathrm{CaCl}_{2}, 1.23 \mathrm{~g} / 1 \mathrm{MgCl}_{2}, 1.68 \mathrm{~g} / 1\right.$ $\mathrm{NaHCO}_{3}, 0.08 \mathrm{~g} / \mathrm{l}$ glucose, $\mathrm{pH}$ 7.7; Fauvel et al., 1999) that maintained the sperm immotile, thus facilitating more precise counting. Sperm cells were counted in a $7 \mu \mathrm{L}$ sample on the haemocytometer at $400 \times$ magnification.

\subsection{Percentage of motile sperm}

This percentage was measured after activation with $2 \mu \mathrm{L}$ of the stored ejaculate with the addition of $1 \mathrm{~mL}$ of UV-sterilised marine water sampled from the storage tanks (see 'Fish sampling and maintenance'). Three microliters of the activated sample were placed on a 12 -well multitest slide (MP Biomedicals, Aurora, $\mathrm{OH}$ ) pre-coated with 1\% polyvinyl alcohol (Sigma-Aldrich) to avoid sperm sticking to the glass slide (Wilson-Leedy and Ingermann, 2007) and were covered with a coverslip. The slide was examined at $200 \times$ magnification, and the percentage of motile sperm in 
the total number of sperm in a visual field was manually counted. The measurements were repeated

160 three times for each sample, leading to repeatability (calculated for each week according to Becker, 161 1984) that was always greater than 0.596. All the samples were analysed by the same trained 162 observer to avoid subjective differences in motility evaluation.

\subsection{Sperm longevity}

Sperm longevity, i.e., time leading to cessation of the progressive movement, was estimated as the time from activation until $\sim 90 \%$ of sperm within the visual field were no longer motile (not showing head or tail movements) (Gage et al., 2004). To this end, $3 \mu \mathrm{L}$ of an activated ejaculate was collected and examined on a 12-well multitest slide (MP Biomedicals, Aurora, OH) at 200× magnification. The measurements were repeated three times for each sample, leading to repeatability (calculated for each week, according to Becker, 1984) always higher than 0.793. All the samples were analysed by the same trained observer to avoid subjective differences in motility evaluation.

\subsection{Sperm fatty acid content}

To determine the fatty acid profile, subsamples of an ejaculate $(500 \mu \mathrm{L})$ were preserved at $-20^{\circ} \mathrm{C}$ until analyses. After thawing, fat was extracted following the method of extraction with methyl-tert-butyl ether (MTBE) (Matyash et al., 2008). After that, an internal standard (13:1 methyl ester) was added to the extract, and direct esterification was performed according to Jenkins (2009). After centrifugation of the esterified sample, the supernatant was injected into Cromatograph Agilent Technologies 7890 A (Agilent Technologies, Santa Clara, CA, USA), with the split at 40 $\mathrm{mL} / \mathrm{min}$ and ratio 160:1. Supelco SP 2560 (Sigma-Aldrich, St. Louis, MO, USA) served as the first capillary column $(75 \mathrm{~m} \times 0.18 \mathrm{~mm}$ internal diameter, $0.14 \mu \mathrm{m}$ film thickness $)$ with hydrogen as a carrier at $0.25 \mathrm{~mL} / \mathrm{min}$. J\&W HP $5 \mathrm{~ms}$ (Agilent Technologies, Santa Clara, CA, USA) was 
thickness) with hydrogen as a carrier at $22 \mathrm{~mL} / \mathrm{min}$ for $2 \mathrm{~min}$ and then $0.18 \mathrm{~mL} / \mathrm{min}$ to $35 \mathrm{~mL} / \mathrm{min}$.

The oven temperature was $45{ }^{\circ} \mathrm{C}$, then it was held for $2 \mathrm{~min}$, raised to $170{ }^{\circ} \mathrm{C}$ at the rate of 50

${ }^{\circ} \mathrm{C} / \mathrm{min}$, held for $25 \mathrm{~min}$, raised at $240{ }^{\circ} \mathrm{C}$ at the rate of $2{ }^{\circ} \mathrm{C} / \mathrm{min}$, and held for $16 \mathrm{~min}$, while the injector and the detector temperatures were set to $270{ }^{\circ} \mathrm{C}$ and $250{ }^{\circ} \mathrm{C}$, respectively.

Fatty acids were identified by comparing the retention time with that of a mixture of 52

standard Fatty Acid Methyl Esters (FAMEs; GLC reference standard: 674; Nu-Chek Prep, Inc., MN, USA) and Menhaden Fish Oil (Supelco, Bellefonte, PA, USA). Amounts of individual FAMEs were expressed as a percentage of the total area of eluted FAMEs. The percentages of saturated fatty acids (SFAs), unsaturated fatty acids (UFAs), monosaturated fatty acids (MUFAs), polyunsaturated fatty acids (PUFAs), and omega-3 and omega-6 fatty acids were also reported.

\subsection{Testosterone profile}

Blood samples were collected from the caudal vein of wild and farmed eels every 2 weeks,

from the week preceding the beginning of stimulation until the $18^{\text {th }}$ hormone stimulation (Fig. 1).

Blood samples were transferred to heparinised tubes, centrifuged $(4000 \times g, 10 \mathrm{~min})$, and stored at $-20{ }^{\circ} \mathrm{C}$ until analysis.

Testosterone concentrations were analysed in plasma following the method of Gaiani et al. (1984). Briefly, $0.1 \mathrm{~mL}$ of plasma was extracted with $5 \mathrm{~mL}$ of diethyl ether by mixing for $30 \mathrm{~min}$ on a rotary mixer. The tubes were centrifuged at $2000 \times g$ for $15 \mathrm{~min}$, and the supernatants were evaporated to dryness under an air-stream suction hood $\left(37^{\circ} \mathrm{C}\right)$. The dry extracts were stored at -20 ${ }^{\circ} \mathrm{C}$.

Testosterone concentration was measured by a radioimmunoassay (RIA) validated by 207 Parmeggiani et al. (2015). The dried extracts were dissolved in RIA buffer (1 mL; $74.26 \mathrm{mmol} / \mathrm{L}$ $\mathrm{Na}_{2} \mathrm{HPO}_{4}, 12.49 \mathrm{mmol} / \mathrm{L}$ EDTA Na, $7.69 \mathrm{mmol} / \mathrm{L} \mathrm{NaN}$ ), containing 0.1\% of BSA (pH 7.5) and were shaken for $10 \mathrm{~min}$. The samples $(0.1 \mathrm{~mL}), 1,2,6,7-3 \mathrm{H}$ testosterone $(0.1 \mathrm{~mL}, 30 \mathrm{pg} /$ tube $)$, and rabbit anti-testosterone serum $(0.1 \mathrm{~mL}, 1: 50000)$ were incubated overnight $\left(4{ }^{\circ} \mathrm{C}\right) ; 1 \mathrm{~mL}$ of a 
211 charcoal-dextran solution (charcoal $0.25 \%$, dextran $0.02 \%$ in phosphate buffer) was then added into

212 the tubes. After $15 \mathrm{~min}$ incubation at $4{ }^{\circ} \mathrm{C}$, the tubes were centrifuged $(15 \mathrm{~min}, 3000 \times \mathrm{g})$, the

213 supernatant was decanted, and radioactivity was immediately measured on a $\beta$-scintillation counter

214 (Packard C1600, PerkinElmer, USA). Cross-reactions of various steroids with the antiserum raised 215 against testosterone were as follows: testosterone (100\%), dihydrotestosterone (25.44\%), 216 androstenedione $(0.6 \%), 11$-ketotestosterone $(0.5 \%)$, and progesterone and cortisol $(<0.0001 \%)$.

217 The sensitivity of the assay was $1.65 \mathrm{pg} /$ tube, the intra- and inter-assay coefficients of variation 218 were $6.7 \%$ and $11.2 \%$, respectively. To determine the parallelism between hormone standards and 219 an endogenous hormone in eel plasma, a pooled sample containing a high testosterone 220 concentration was serially diluted (1:1-1:8) with RIA buffer. A regression analysis was conducted 221 to determine possible correlation between the two hormone concentrations in the same assay $\left(r^{2}=\right.$ $2220.98, P<0.01)$. The results were expressed in $\mathrm{ng} / \mathrm{mL}$. In all the sperm quality analyses, the operator 223 was blinded to the identity of a subject and its group affiliation.

\subsection{Statistical analyses}

Data were analysed by univariate linear mixed models (LMM; with restricted maximum 227 likelihood estimation) in RStudio, version 1.1.447, using the function 'lme' of the 'nlme' package 228 (Pinheiro et al., 2016). Sperm density, spermatocrit, sperm viability, sperm longevity, the 229 testosterone concentration, and fatty acid content were regarded, alternatively, as dependent 230 variables. Male origin (wild or farmed), sampling week, time from hormone injection to stripping 231 (24 or 48 hours), and the interaction between the origin and week were all considered fixed factors. To account for repeated measurements on individual males, male identity (ID) (nested within origin) was included as a random factor with an estimate of random intercepts for each subject.

234 Because the usual asymptotic inferential results for linear models may not hold in this dataset owing 235 to the limited number of observations, the $P$ values of the LMMs were evaluated via a resamplingbased strategy (1000 random permutations, see Kherad-Pajouh and Renaud, 2009), by means of the 
237 'permmodels' function of the 'predictmeans' package (Luo et al., 2014). At the final step, all non238 significant interaction terms were removed from the full models to achieve minimal adequate 239 models (Crawley, 2005). Furthermore, for the sake of simplicity, only results of the latter are 240 reported. In accordance with the permutation strategy applied to the main LMM, pairwise post hoc 241 tests were also performed via the resampling-based strategy (1000 random permutations), using the 242 function 'pairwise.perm.t.test' of the package 'RVAideMemoire' (Hervé, 2018). The $P$ values were 243 adjusted for multiple testing by the method of Benjamini and Hochberg (1995). The relation 244 between the two measures of sperm concentration (haemocytometer and spermatocrit) was tested 245 through a simple linear regression $(\mathrm{lm})$.

\section{Results}

\subsection{Sperm concentration}

The two measurements of sperm concentration, by means of the haemocytometer and spermatocrit, highly correlated in all the experimental weeks (Regression estimate: 0.743 ; st. error: $0.055 ; t$ value: $13.43, P<0.001, \mathrm{R}^{2}=0.744, \mathrm{df}=62$. Regression function: $\left.\mathrm{y}=3.123+0.743 \mathrm{x}\right)$. There was an effect of the sampling week only for spermatocrit values, with lesser values after the $17^{\text {th }}$ week compared to the $13^{\text {th }}$ week $(P=0.04)$. Neither an effect of the male origin nor an interaction between male origin and sampling week was observed (Table 1; Fig. 2 a, b).

\subsection{Percentage of motile sperm}

There was not any difference between wild and farmed eels for the percentage of motile sperm (Table 1). There was only an effect of the sampling week, with a greater percentage of motile sperm after the $17^{\text {th }}$ week (mean $\left.\pm \mathrm{SE}=61.3 \% \pm 0.4 \%\right)$ compared to the $13^{\text {th }}$ week $($ mean $\pm \mathrm{SE}=$ $36.2 \% \pm 0.6 \%)$ 
There was an effect on sperm longevity depending on the origin of males (Table 1), with 264 wild caught eels having greater values of sperm longevity. There was an effect of the time interval 265 between hormone injection and sperm quality analyses (Table 1): after the $13^{\text {th }}$ week, sperm 266 longevity was on average less in those ejaculates analysed at 48 instead of 24 hours after hormone 267 injection (mean values in Table S1 in Supplementary Material).

There was a marginal effect of the sampling week $(P=0.045$, Table 1$)$, irrespective of the origin of males with a trend of an increase in sperm longevity, with a peak at approximately after the $16^{\text {th }}$ week (Fig. 3).

\subsection{Sperm fatty acid content}

There was an effect of the origin of male eels (wild compared with farmed) on sperm SFAs and UFAs was seen (Table 2), with greater concentrations of UFAs and lesser concentrations of SFAs in the wild males compared to farmed eels (Tables 2 and S2). In addition, the percentages of omega-3 and of omega- 6 fatty acids were affected by the origin of eels (Table 2), but in the opposite direction for the two fatty acid types: omega-3 concentrations were greater in farmed males, whereas omega-6 concentrations were greater in wild eels (Fig. 4 a, b).

There was also an effect of the sampling week on MUFAs, PUFAs, and omega-6 fatty acids

(Table 2). The proportion (percentage) of MUFAs was greater during initial sampling week 13

when compared to week 16 (13 compared with 16: adjusted $P=0.020)$. The concentration of PUFAs was greater in week 13 when compared to weeks 15 and 16 (adjusted $P=0.04$ ). The concentration of $\omega-6$ fatty acids was greater in week 13 when compared to final weeks 16 and 17 (adjusted $P=0.047)$. Detailed mean values are reported in Table S2 (Supplementary Material).

\subsection{Testosterone profile}

The mean $\pm \mathrm{SE}$ of the testosterone concentrations prior to stimulation was $0.38 \pm 0.05$

$\mathrm{ng} / \mathrm{mL}$ among the farmed males and $0.45 \pm 0.15 \mathrm{ng} / \mathrm{mL}$ among the wild males. The concentration 
increased after the first injections of hCG, thus reaching the mean $\pm \mathrm{SE}$ of $3.43 \pm 0.70 \mathrm{ng} / \mathrm{mL}$ among the farmed male eels and $4.09 \pm 1.43 \mathrm{ng} / \mathrm{mL}$ among the wild male eels. This change was

291 followed by a gradual decrease until the end of the experiment. There was no difference in 292 testosterone profiles between wild and farmed male eels, and only an effect of the sampling week, 293 irrespective of the origin of male eels, was observed (LMM: origin, $\mathrm{F}_{1,11}=0.036, P=0.832$; week: $294 \mathrm{~F}_{8,86}=11.350, p<0.01$; interaction origin*week: $\mathrm{F}_{8,86}=0.439, p=0.904$; see Figure $\mathrm{S} 1$ in 295 Supplementary Material).

\section{Discussion}

The results of the present study indicate that the different origins of the male European eels partly influence the quality of the ejaculates. Wild caught eels (i.e., caught at a natural site before the hormonal induction) had a greater sperm longevity during hormone stimulation.

In the present study, sperm longevity appeared to be the most sensitive sperm variable because there was an effect of the origin of male eels (wild or farmed), by the sampling week, and by the time interval between injection and stripping. Nevertheless, the greatest sperm longevity occurred in wild eels at 16 weeks after the beginning of hormone stimulation, later than the peak in sperm concentration (weeks $13^{\text {th }}-14^{\text {th }}$ ). This finding suggests that in the present study, sperm longevity had a greater but slower response to hormone stimulation than did sperm concentration. For sperm concentration, there were greater spermatocrit values in wild caught eels only at 13 weeks after the beginning of hormonal stimulation. In contrast to another study on the European eel (Pérez et al., 2000), it was highlighted that there was a significant increase in sperm concentration as early as 6 weeks after the beginning of hormone stimulation, a further increase 311 after 8 weeks, and relatively consistent values until the last week of analyses $\left(15^{\text {th }}\right)$. The experimental regimens of the two studies, however, differ in the dose of hCG administered [which was higher in the study by Pérez et al. (2000): 1.5 compared with $1.0 \mathrm{UI} / \mathrm{g}$ in the present study] as 314 well as in the temperature of animal maintenance $\left(20{ }^{\circ} \mathrm{C}\right.$ in the previous compared with $15{ }^{\circ} \mathrm{C}$ in the 
315 present study). Both of these methodological inconsistencies may be the reasons for the later 316 increase in sperm density in the present study. The hormone dose and injection frequency influence 317 both the duration of spermatogenesis and the spermiation period in the European eel (Tomkiewicz 318 et al., 2011). Furthermore, temperature modulates testis steroidogenesis in the European eel (with 319 an effect on maturation) and there is a delay in spermatogenesis initiation when there are thermal 320 regimens with lesser temperatures imposed (Peñaranda et al., 2016).

As recently demonstrated by Sørensen et al. (2013), in the present study, there was also values for the variables of sperm concentration by means of the haemocytometer and spermatocrit that were highly correlated.

Of note, results of the present study also indicate that the difference in sperm quality between wild caught and farmed male eels was associated with differences in some sperm fatty acids concentrations. The sperm of wild males, which have greater longevity than that of farmed males, also contains greater concentrations of UFAs, according to the results of the present study. The presence of UFAs in cellular membranes is important for maintenance of the properties of the lipid bilayer (Farooqui et al., 2000), and the lipids of the spermatozoan membrane are key determinants of fluidity and flexibility, and thus, of successful fertilisation (Lenzi et al., 1996). In

331 fish, the lipid composition of the sperm membrane is closely related to the functionality of spermatozoa, in particular to sperm viability, sperm motility duration, and sperm cryoresistance 333 (Lahnsteiner et al., 2009). In the rainbow trout Oncorhynchus mykiss, sperm UFAs have a positive 334 influence on sperm viability during storage of spermatozoa and on sperm motility after activation 335 (Lahnsteiner et al., 2009). Conversely, the sperm of wild male eels in the present study had lesser 336 amounts of SFAs, and this result seems to be consistent with the findings of Mansour et al. (2011) regarding Salvelinus alpinus, where SFA levels were in lesser amounts with high-fertility semen.

338 Furthermore, in the present study there was an effect of the treatment on the percentages of omega3393 and omega- 6 fatty acids, with the sperm of farmed males having greater concentrations of omega3403 fatty acids and sperm of wild caught males having a greater concentration of omega- 6 fatty acids. 
341 Considering sperm fatty-acid composition of fish spermatozoa is often affected by the diet 342 (Pustowka et al., 2000; Vassallo-Agius et al., 2001; Butts et al., 2015), this opposite effect on 343 omega-3 and omega- 6 fatty acids might be due to the difference in diets that the two groups of 344 males consumed during the pre-experimental period. Farmed male eels were fed with artificial fish 345 meal rich in omega-3 fatty acids (ALTERNA EEL, Skretting). This hypothesis is supported by 346 Butts et al. (2015), where it was reported that there were similar percentages of omega-3 and 347 omega- 6 fatty acids in the milt of male European eels fed improved commercial diets. Taken 348 together with the previous results on European eels (Pérez et al., 2000), and the present findings 349 seem to support the idea that sperm of greater quality (that of the wild males in the present study) 350 have a lesser percentage of omega-3 fatty acids and a lesser omega-3/omega-6 ratio. Butts et al. 351 (2015) compared the sperm performance of male European eels fed different artificial diets and 352 concluded that lesser concentrations of total omega-3 fatty acids in sperm samples correlate with 353 the least sperm motility and volume. Results of the present study indicate that other dietary 354 components or the prolonged maintenance of farmed males in captivity may be responsible for the 355 enhanced performance on longevity of wild-male sperm. In the $13^{\text {th }}$ week, in which sperm analyses 356 were performed for two different periods after hormone injection ( 24 or 48 hours later), there was 357 an influence of the time since hormone injection on sperm longevity, with males stripped 24 hours 358 after the injection having greater sperm longevity than those stripped 48 hours after injection. These 359 results are consistent with the findings in other studies on the European eel and confirm that 360 stripping within 24 hours after injection is the best procedure for obtaining sperm of greater quality 361 (Pérez et al., 2000; Asturiano et al., 2006). As for the plasma testosterone concentration in the present study, as expected (Baeza et al., 363 2015), there was a significant increase after the beginning of hormone stimulation. Wild and farmed 364 male eels, however, did not manifest a differential response to hormone stimulation in terms of 365 plasma testosterone concentrations in the present study. In fish, gonadotropin stimulation (mainly 366 FSH) induces the secretion of androgens (e.g., testosterone and 11-ketotestosterone) during the 
367 initial stage of male gametogenesis (Nagahama, 1994; Mananos et al., 2008). In a number of 368 species, plasma concentrations of testosterone and 11-ketotestosterone are greater during the later 369 stages of spermatogenesis and rapidly decrease after the onset of spermiation (Nagahama, 1994). As 370 reported in the review by Tokarz et al. (2015) and in the study by Lokman and Young (1998), in 371 male eels, testosterone can be considered a precursor of 11-ketotestosterone, the prevalent androgen 372 in fish. As further support of this hypothesis, Baeza et al. (2015) reported similar trends of 373 testosterone and 11-ketotestosterone concentrations throughout different stages of eel testis 374 development. Accordingly, in the present study, there was an immediate increase in testosterone 375 concentrations in the two groups of animals already at the second injection of hCG: levels $\sim 3$ $376 \mathrm{ng} / \mathrm{mL}$ at the peak and a subsequent decrease. In the study by Huertas et al. (2006), the peak of 377 testosterone concentrations occurred after the fifth week, with concentrations of $\sim 8 \mathrm{ng} / \mathrm{mL}$. The 378 observed difference between the results of Huertas et al. (2006) and those in the present study might 379 be due to the use of different eel populations as well as to the different procedures for hormonal 380 stimulation.

\section{Conclusions}

To our knowledge, this is the first study on sperm quality in European eels that takes into account the effect of the different origins of hormonal stimulated males (wild-caught compared with farmed) on sperm quality. Results of the present study indicate that wild-caught males have a greater sperm quality in terms of longevity during hormonal stimulation than do sperm of farmed 387 eels; however, no difference in sperm density, percentage of motile sperm, and plasma testosterone 388 concentrations was detected. Overall, findings in the present study suggest that farmed male eels could still be viable substitutes of wild-caught males to improve the production of European eels, an

390 economically relevant species for which there is a major decrease of wild stocks.

\section{Funding}


This research was supported by Universities of Padova and Bologna grants (institutional funds) to

D. Bertotto and O. Mordenti.

\section{References}

Asturiano, J.F., Marco-Jimenez, F., Pérez, L., Balasch, S., Garzon, D.L., Peñaranda, D.S., Vicente, J.S., Viudes-de-Castro, M.P., Jover, M., 2006. Effects of hCG as spermiation inducer on European eel semen quality. Theriogenology 66, 1012-1020.

Baeza, R. Mazzeo I., Vílchez M.C., Gallego V., Peñaranda D.S., Pérez L., Asturiano J.F. 2015. Relationship between sperm quality parameters and the fatty acid composition of the muscle, liver and testis of European eel. Comparative Biochemistry and Physiology Part A: Molecular \& Integrative Physiology 181, 79-86.

Becker, W.A., 1984. A manual of quantitative genetics. Pullman Academic Enterprises, Washington DC.

Benjamini, Y. and Hochberg, Y., 1995. Controlling the false discovery rate: a practical and powerful approach to multiple testing J. Royal Stat. Soc. 57, 289-300.

Bevacqua, D., Melià, P., Gatto, M., De Leo, G.A., 2015. A global viability assessment of the European eel. Glob. Change Biol. 21(9), 3323-3335.

Butts, I.A.E., Baeza, R., Støttrup, J.G., Krüger-Johnsen, M., Jacobsen, C., Pérez, L., Asturiano, J.F., Tomkiewicz, J., 2015. Impact of dietary fatty acids on muscle composition, liver lipids, milt composition and sperm performance in European eel. Comp. Biochem. Physiol. A, Mol. Integr. Physiol. 183, 87-96.

Butts I.A.E., Sørensen S.R., Politis S. N., Tomkiewicz J., 2016. First-feeding by European eel larvae: A step towards closing the life cycle in captivity. Aquaculture 464, 451-458.

Costa-Dias, S., Lobón-Cerviá, J., 2008. Diel feeding activity and intensity during an annual cycle of the European eel Anguilla anguilla (L.) in a Cantabrian stream. Knowl. Manag. Aquat. Ec. 390-391, 1-9. 
Crawley, M.J., 2005 Statistics. An introduction using R. J Wiley \& Sons, Chichester.

419 Dekker, W., Casselman, J.M., Cairns, D.K., Tsukamoto, K., Jellyman, D., Lickers, H., 2003. Worlwide decline of eel resources necessities immediate action: Quebec declaration of concern. Fisheries 28, 28-30.

Dollerup, J., Graver, C.M., 1985. Repeated induction of testicular maturation and spermiation, alternating with periods of feeding and growth in silver eels, Anguilla anguilla (L.). Dana

Durif, C., Dufour, S., Elie, P., 2005. The silvering process of Anguilla anguilla: a new classification from the yellow resident to the silver migrating stage. J. Fish Biol. 66, 1025-1043.

Farooqui, A.A., Horrocks, L.A., Farooqui, T., 2000. Glycerophospholipids in brain: their metabolism, incorporation into membranes, functions, and involvement in neurological disorders. Chem. Phys. Lipids 106(1), 1-29.

Fauvel, C., Savoye, O., Dreanno, C., Cosson, J., Suquet, M., 1999. Characteristics of sperm of captive seabass in relation to its fertilisation potential. J. Fish Biol. 54, 356-369.

Gage, M.J.G., Macfarlane, C.P., Yeates, S., Ward, R.G., Searle, J.B., Parker, G.A. 2004. Spermatozoal traits and sperm competition in Atlantic salmon: relative sperm velocity is the primary determinant of fertilization success. Curr. Biol. 14, 44-47.

Gaiani, R., Chiesa, F., Mattioli, M., Nannetti, G., Galeati, G., 1984. Androstenedione and testosterone concentrations in plasma and milk of the cow throughout pregnancy. J. Reprod. Fertil. 70, 55.

Gallego, V., Mazzeo I., Vílchez M.C., Peñaranda D.S., Carneiro P.C.F., Pérez L., Asturiano J.F. 2012. Study of the effects of thermal regime and alternative hormonal treatments on the reproductive performance of European eel males (Anguilla anguilla) during induced sexual maturation. Aquaculture 354, 7-16

IUCN 2015. The IUCN Red List of Threatened Species. Version 2015-4. 
443 Huertas, M., Scott, A. P., Hubbard, P. C., Canário, A. V. M., Cerdà, J. 2006. Sexually mature European eels (Anguilla anguilla L.) stimulate gonadal development of neighbouring males: Possible involvement of chemical communication. Gen. Comp. Endocrinol. 147, 304-313.

Hervé M., 2018. Testing and Plotting Procedures for Biostatistics. R package version 0.9-69-3.

Jenkins, T.C., 2009. Technical note: Common analytical errors yielding inaccurate results during analysis of fatty acids in feed and digesta samples. J. Dairy Sci. 93(3), 1170-1174.

Kherad-Pajouh, S., Renaud, O. 2009. An exact permutation method for testing any effect in balanced and unbalanced fixed effect ANOVA. Comput. Stat. Data Anal. 54, 1881-1893.

Lahnsteiner, F., Mansour, N., McNiven, M., Richardson, G., 2009. Fatty acids of rainbow trout (Oncorhynchus mykiss) semen: Composition and effects on sperm functionality. Aquaculture 298, 118-24.

Lenzi, A., Picardo, M., Gandini, L., Dondero, F., 1996. Lipids of the sperm plasma membrane: from polyunsaturated fatty acids considered as markers of sperm function to possible scavenger therapy. Hum. Reprod. Update 2, 246-256.

Luo, D., Ganesh S., Koolaard J., 2014. Calculate Predicted Means for Linear Models. R package version 0.99 .

Mañanós, E., Duncan, N., Mylonas C.C, 2008. Reproduction and control of ovulation, spermiation tionship between fertility and fatty acid profile of sperm and eggs in Arctic char, Salvelinus alpinus. Aquaculture 318, 371-378. 
Matyash, V., Liebisch, G., Kurzchalia, T.V., Andrej Shevchenko, A., Schwudke, D., 2008. Lipid extraction by methyl-tert-butyl ether for high-throughput lipidomics. J. Lipid. Res. 49, 1137-1146.

Migaud, H., Bell, G., Cabrita, E., McAndrew, B., Davie, A., Bobe, J., Herráez, M.P., Carillo, M., 2013. Gamete quality and broodstock management in temperate fish. Rev. Aquac. 5, 194223.

Mordenti, O., Di Biase, A., Bastone, G., Sirri, R., Zaccaroni, A., Parmeggiani, A., 2013. Controlled reproduction in the wild European eel (Anguilla anguilla): two populations compared. Aquacult. Int. 21, 1045-1063.

Mordenti, O., Di Biase, A., Casalini, A., Emanuele, P., Melotti, P., Roncarati, A., 2016. Growth performances and natural diet of European eel (Anguilla anguilla L.) reared in muddy and sandy ponds. Aquat. Living Resour. 29, 105.

Nagahama, Y., 1994. Endocrine regulation of gametogenesis in fish. Int. J. Dev. Biol. 38, 217-229.

Ohta, H., Kagawa, H., Tanaka, H., Okuzawa, K., Hirose, K., 1996. Changes in fertilization and hatching rates with time after ovulation induced by $17 \alpha, 20 \beta$-dihydroxy-4-pregnen-3-one in the Japanese eel, Anguilla japonica. Aquaculture 139, 291-301.

Palstra, A.P., Cohen, E.G.H., Niemantsverdriet, P.R.W., Van Ginneken, V.J.T., Van den Thillart G.E.E.J.M., 2005. Artificial maturation and reproduction of European silver eel: Development of oocytes during final maturation. Aquaculture 249, 533-547.

Parmeggiani, A., Govoni, N., Zannoni, A., Di Biase, A., Sirri, R., Forni, M., Mandelli, M., Mordenti, O., 2015. Effect of photoperiod on endocrine profiles and vitellogenin expression in European eels Anguilla anguilla during artificially induced ovarian development. Theriogenology 83, 478-484.

Peñaranda, D.S., Morini, M., Tveiten, H., Vílchez, M.C., Gallego, V., Dirks, R.P., van den Thillart, G.E.E.J.M., Pérez, L., Asturiano, J.F., 2016. Temperature modulates the testis steroidogenesis in European eel. Comp. Biochem. Physiol. A 197, 58-67. 
Peñaranda, D.S., Pérez, L., Gallego, V., Jover, M., Tveiten, H., Baloche, S., Dufour, S., Asturiano, J.F., 2010. Molecular and physiological study of the artificial maturation process in European eel males: from brain to testis. Gen. Comp. Endocrinol. 166, 160-171.

Pérez, L., Asturiano, J.F., Tomás, A., Zegrari, S., Barrera, R., Espinós, F.J., Navarro, J.C., Jover, M., 2000. Induction of maturation and spermiation in the male European eel: assessment of sperm quality throughout treatment. J. Exp. Biol. 57, 1488-1504.

Pinheiro, J., Bates, D., DebRoy, S., Sarkar, D. and R Core Team, 2016. Linear and non linear mixed effects models. R package version 3.1-137.

Pustowka, C., McNiven, M.A., Richardson, G.F., Lall, S.P., 2000. Source of dietary lipid affects sperm plasma membrane integrity and fertility in rainbow trout Oncorhynchus mykiss (Walbaum) after cryopreservation. Aquaculture Res. 31, 297-305.

Rurangwa, E., Kime, D.E., Ollevier, F., Nash, J.P., 2004. The measurement of sperm motility and factors affecting sperm quality in cultured fish. Aquaculture 234 (1-4), 1-28.

Sørensen, S.R., Gallego, V., Pérez, L., Butts, I.A.E., Tomkiewicz, J., Asturiano, J.F., 2013. Evaluation of methods to determine sperm density for the European eel, Anguilla Anguilla. Reprod. Domest. Anim. 48 (6), 936-944.

Sorensen, S.R., Tomkiewicz J., Munk P., Butts I.A.E., Nielsen A., Lauesen P., Graver C. 2016. Ontogeny and growth of early life stages of captive-bred European eel. Aquaculture, 456, $50-61$.

Stone, R., 2003. Freshwater eels are slip-sliding away. Science 302, 221-222.

Tanaka, H., Kagawa, H., Ohta, H., 2001. Production of leptocephali of Japanese eel (Anguilla japonica) in captivity. Aquaculture 201, 51-60.

Tokarz, J., M $\square$ ller, G., de Angelis, M. H., Adamski, J., 2015. Steroids in teleost fish: A functional point of view. Steroids, 103, 123-144. 
519 Tomkiewicz, J., Kofoed, T.M.N., Pedersen, J.S., 2011. Assessment of testis development during induced spermatogenesis in the European eel Anguilla anguilla. Mar. Coast. Fish. 3, 106-118.

522 Vassallo-Agius, R., Watanabe, T., Yoshizaki, G., Satoh, S., Takeuchi, Y., 2001. Quality of eggs and spermatozoa of rainbow trout fed a-3essential fatty acid-deficient diet and its effects on the lipid and fatty acid components of eggs, semen and livers. Fish. Sci. 67, 818-827.

525 Wilson-Leedy, J.G., Ingermann, R.L., 2007. Development of a novel CASA system based on open source software for characterization of zebrafish sperm motility parameters. Theriogenology 67, 661-672. 
546 Results of LMMs (minimal adequate models) on values for sperm variables; Male origin: wild547 caught compared with farmed; sampling week: sperm sampling from the $13^{\text {th }}$ week after beginning 548 of hormone stimulation to the 17th week; F-test statistics, numerator degrees of freedom (Num df) 549 and denominator degrees of freedom (Den df) are reported; $P$ values are calculated through a 550 permutation-based strategy (1000 permutations), and the values that are different at presented in 551 bold font

\begin{tabular}{llcccc}
\hline & fixed factors & $\mathrm{F}$ & Num df & Den $\mathrm{df}$ & $p$ \\
\hline Density & male origin & 0.847 & 1 & 11 & 0.347 \\
& week & 0.932 & 4 & 11 & 0.483 \\
& time from injection & 2.171 & 1 & 46 & 0.174 \\
\hline \multirow{2}{*}{ Spermatocrit } & male origin & 2.011 & 1 & 11 & 0.131 \\
& week & 5.000 & 4 & 11 & $\mathbf{0 . 0 0 2}$ \\
& time from injection & 3.560 & 1 & 46 & 0.081 \\
\hline \% Motile & male origin & 1.718 & 1 & 11 & 0.191 \\
& week & 6.477 & 4 & 11 & $\mathbf{0 . 0 0 2}$ \\
& time from injection & 2.131 & 1 & 46 & 0.147 \\
\hline Longevity & male origin & 5.248 & 1 & 11 & $\mathbf{0 . 0 1 9}$ \\
& week & 2.644 & 4 & 11 & $\mathbf{0 . 0 4 5}$ \\
& time from injection & 6.499 & 1 & 46 & $\mathbf{0 . 0 2 8}$ \\
\hline
\end{tabular}

Table 2

556 Results of LMMs (simplified minimal adequate models) on fatty acid content of sperm; Origin: 557 wild compared with farmed males; week: sperm sampling from the $13^{\text {th }}$ week after beginning of 558 hormone stimulation to the $17^{\text {th }}$ week; F-test statistics, numerator degrees of freedom (Num df) and 559 denominator degrees of freedom (Den df) are reported; $P$ values were calculated via a permutation560 based strategy (1000 permutations), and those values that are different are presented in bold

\begin{tabular}{llcccc}
\hline & fixed factors & $\mathrm{F}$ & Num df & Den df & $P$ \\
\hline \multirow{2}{*}{ SFA } & male origin & 3.977 & 1 & 11 & $\mathbf{0 . 0 1 2}$ \\
& week & 1.365 & 4 & 41 & 0.278 \\
\hline \multirow{2}{*}{ UFA } & male origin & 10.818 & 1 & 11 & $\mathbf{0 . 0 0 1}$ \\
& week & 0.604 & 4 & 41 & 0.755 \\
\hline \multirow{2}{*}{ MUFA } & male origin & 3.209 & 1 & 11 & 0.081 \\
& week & 5.265 & 4 & 41 & $\mathbf{0 . 0 0 5}$ \\
\hline
\end{tabular}




\begin{tabular}{llcccc} 
PUFA & male origin & 0.300 & 1 & 11 & 0.660 \\
& week & 2.675 & 4 & 41 & $\mathbf{0 . 0 2 5}$ \\
\hline OMEGA 3 & male origin & 45.160 & 1 & 11 & $\mathbf{0 . 0 0 1}$ \\
& week & 0.864 & 4 & 41 & 0.562 \\
\hline OMEGA 6 & male origin & 80.070 & 1 & 11 & $\mathbf{0 . 0 0 1}$ \\
& week & 5.822 & 4 & 41 & $\mathbf{0 . 0 0 2}$ \\
\hline
\end{tabular}

\section{$563 \quad$ Figure legends}

564 Fig. 1. Timeline of the experimental procedure

565 Fig. 2. Sperm concentrations in wild (ם) and farmed ( $\square$ ) male eels during successive sampling

566 weeks; (a) Sperm density in a haemocytometer and (b) according to spermatocrit; Reported data are

567 means $\pm \mathrm{SE}$

568 Fig. 3. Sperm longevity in wild ( $\square)$ and farmed ( $\square$ ) male eels during successive sampling weeks;

569 Reported data are means \pm SE.Fig. 4. Percentages of (a) omega-3 and (b) omega-6 fatty acids in 570 wild ( $\square$ ) and farmed ( $\square$ ) male eels during successive sampling weeks; Reported data are means \pm 571 SE

573 Supplementary material

574 Fig. S1. Testosterone concentrations in wild ( $\square)$ and farmed ( $\square$ ) male eels during successive 575 sampling weeks; Reported results are means $\pm \mathrm{SE}$

\section{Table S1}

577 Descriptive statistics for sperm concentration and performance measured in wild and farmed males 578 in each sampling week

\section{Table S2}

580 Descriptive statistics for the fatty acid content in the sperm of wild and farmed male eels in each 581 sampling week 
$\sum_{\substack{1 \\ \frac{1}{1}}}$

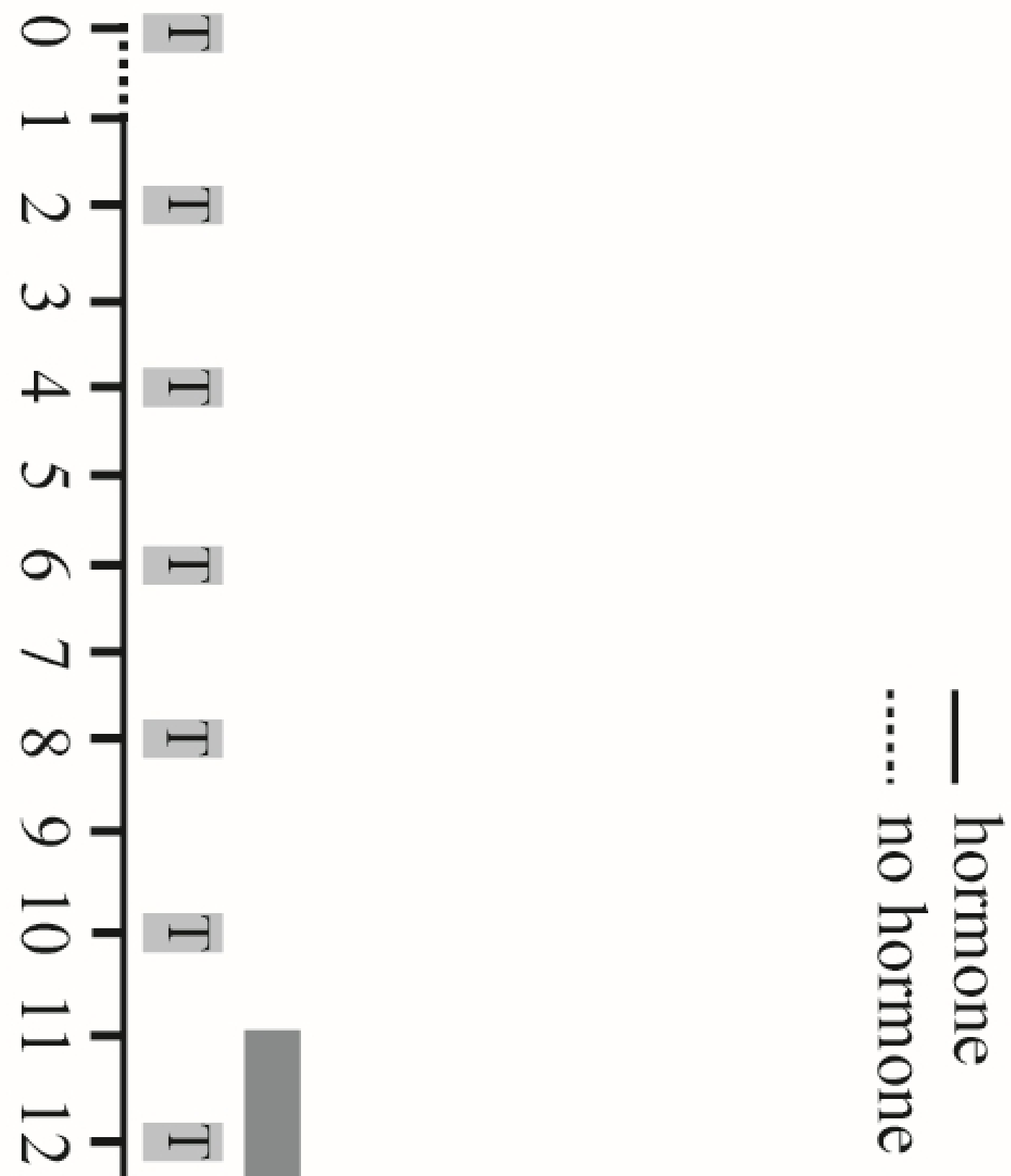

$\omega-\pi$

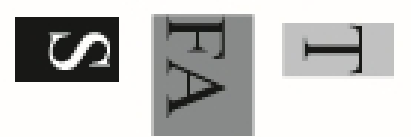

$\Delta-1$
$\sigma_{2}$

网

(

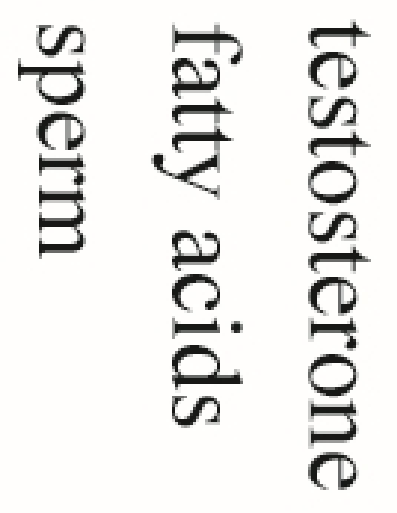



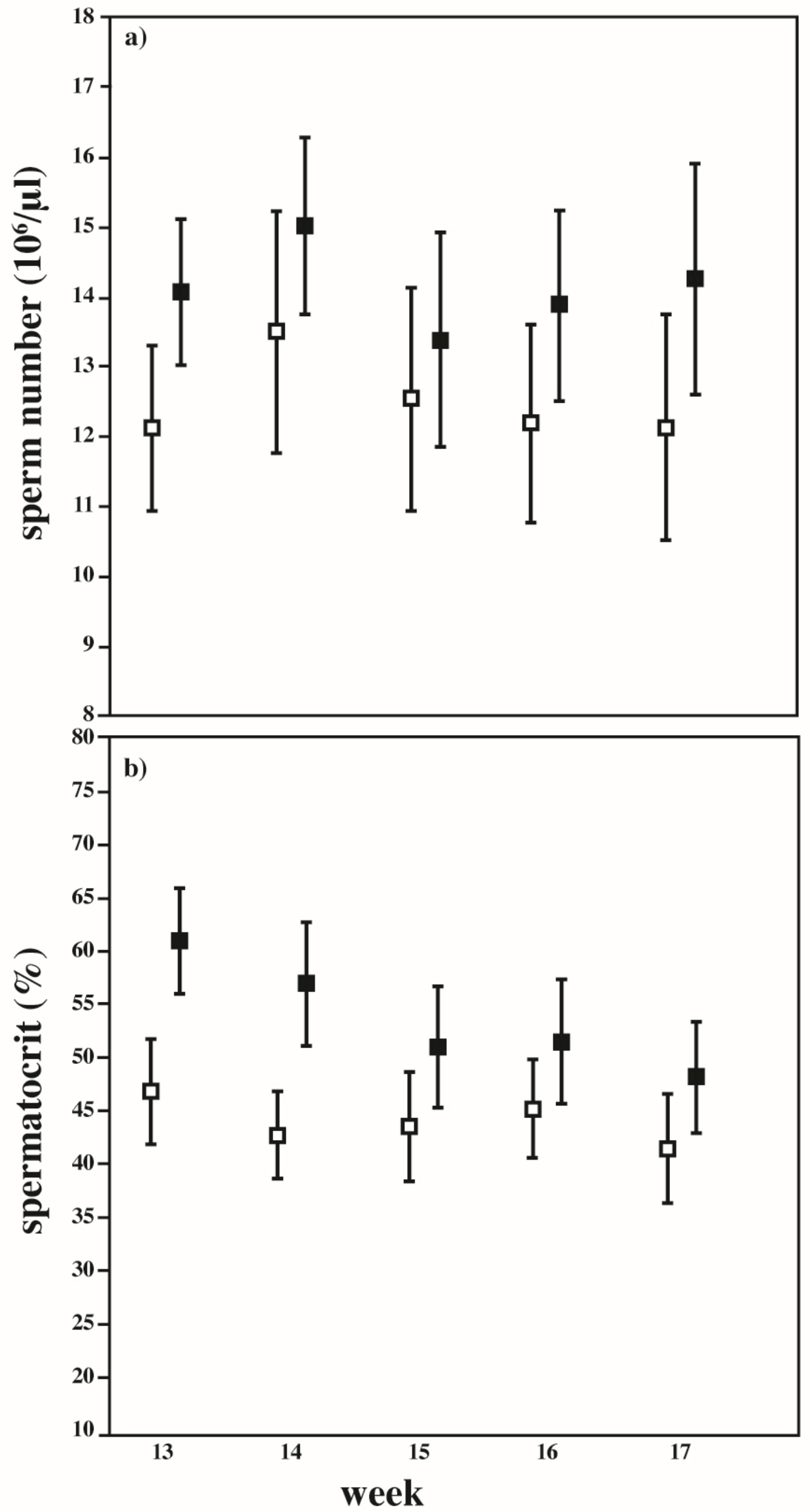


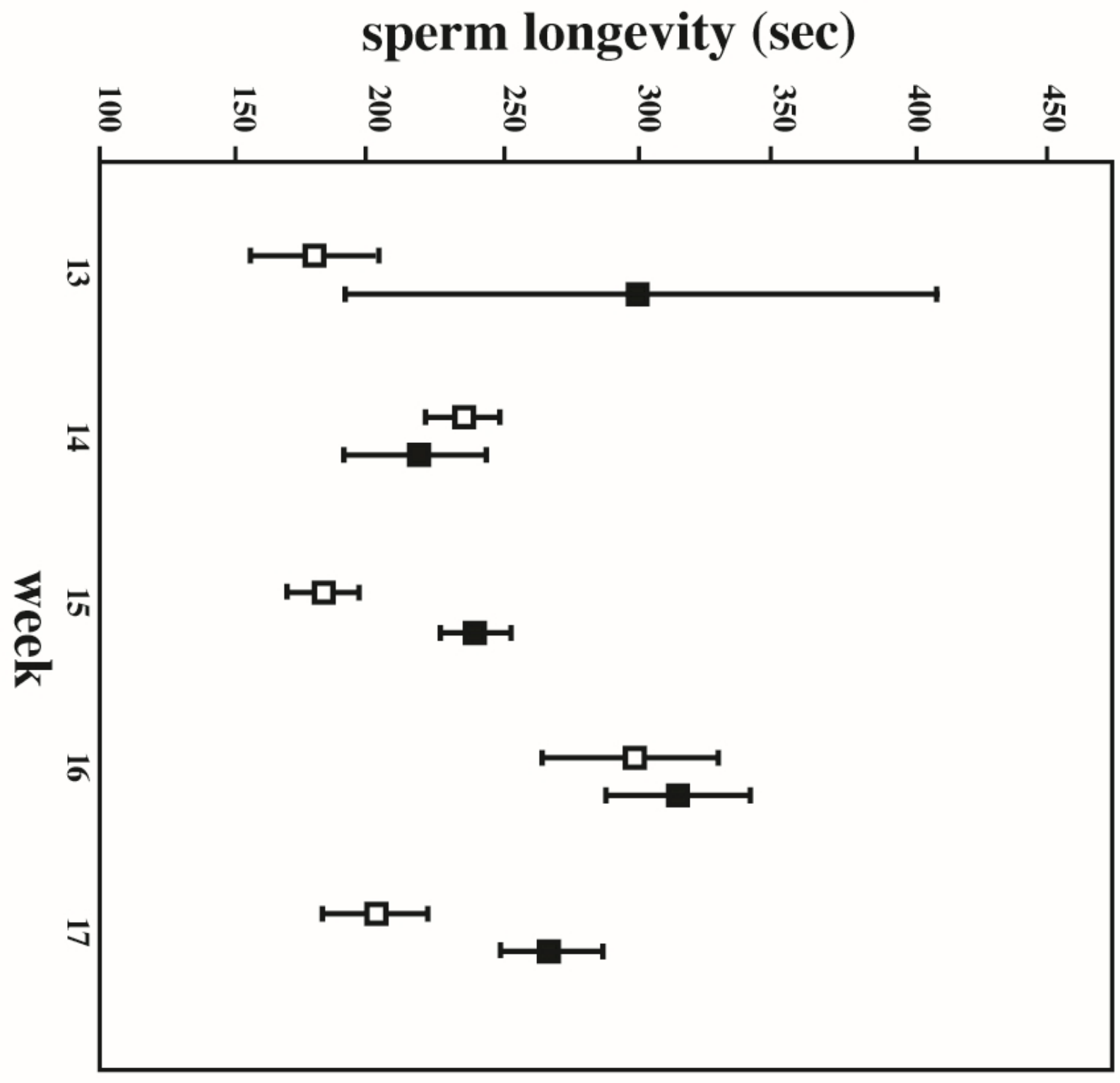



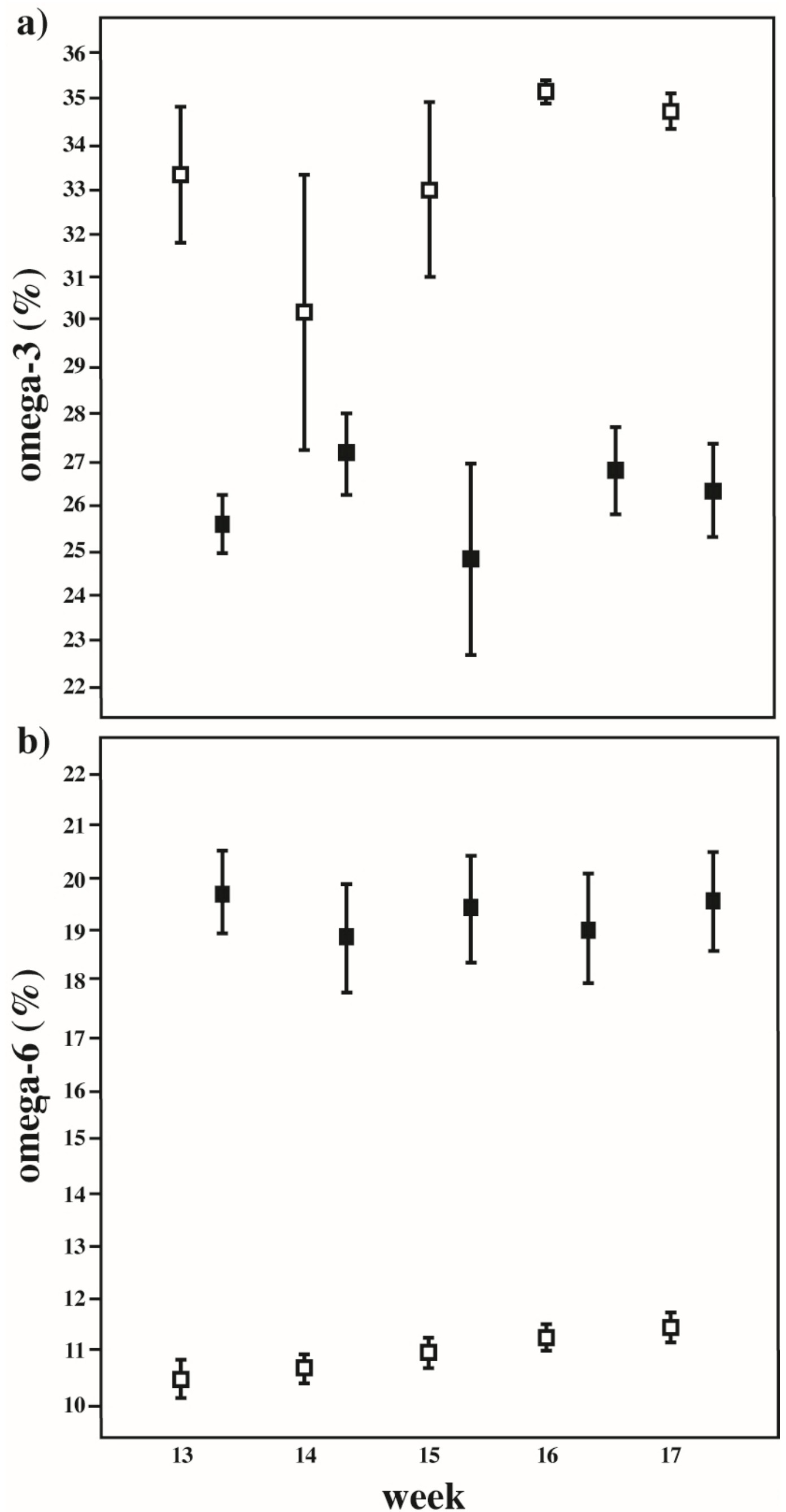


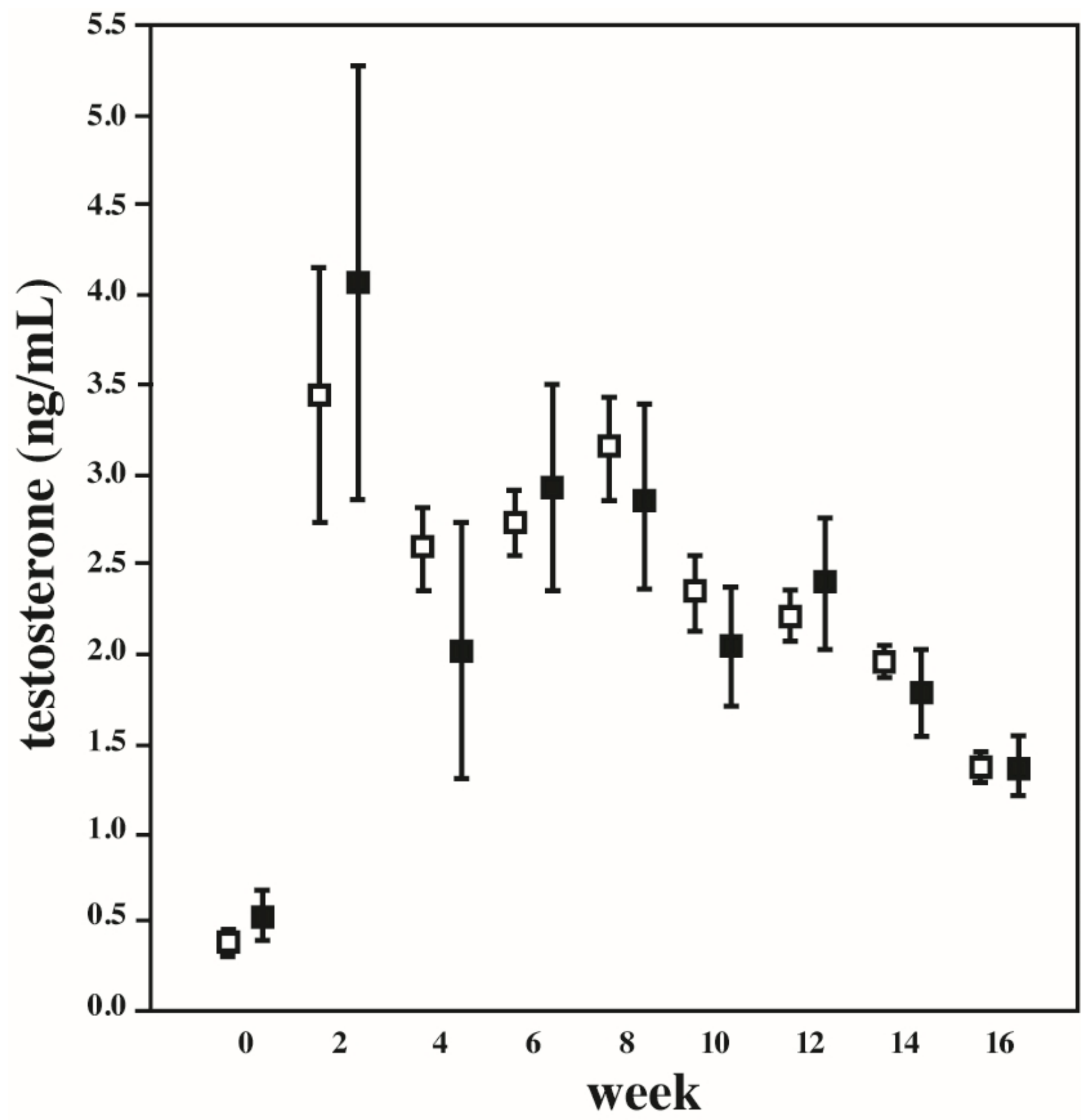


Table S1. Descriptive statistics (mean \pm SD) and number of samples analysed for sperm density, spermatocrit, \% of mobile sperm and sperm longevity, in each experimental week on both wild caught and farmed males.

\begin{tabular}{|c|c|c|c|c|c|c|c|c|}
\hline & \multicolumn{4}{|c|}{ Sperm count $\left(10^{6} / \mu \mathrm{l}\right)$} & \multicolumn{4}{|c|}{ Spermatocrit (\%) } \\
\hline & wild & & farmed & & wild & & farmed & \\
\hline & mean \pm SD & $\mathrm{N}$ & mean \pm SD & $\mathrm{N}$ & mean \pm SD & $\mathrm{N}$ & mean \pm SD & $\mathrm{N}$ \\
\hline \multicolumn{9}{|l|}{ week } \\
\hline 13 & $14.07 \pm 2.58$ & 6 & $12.10 \pm 3.14$ & 7 & $60.68 \pm 12.24$ & 6 & $46.55 \pm 13.08$ & 7 \\
\hline 14 & $15.02 \pm 3.10$ & 6 & $13.52 \pm 4.14$ & 6 & $56.69 \pm 14.08$ & 6 & $41.42 \pm 11.63$ & 6 \\
\hline 15 & $13.36 \pm 3.76$ & 6 & $12.54 \pm 4.24$ & 7 & $50.73 \pm 13.95$ & 6 & $43.23 \pm 13.65$ & 7 \\
\hline 16 & $13.87 \pm 3.37$ & 6 & $12.18 \pm 3.76$ & 7 & $51.25 \pm 14.46$ & 6 & $44.89 \pm 12.32$ & 7 \\
\hline \multirow[t]{4}{*}{17} & $14.25 \pm 4.09$ & 6 & $12.11 \pm 4.26$ & 7 & $47.89 \pm 12.70$ & 6 & $41.21 \pm 13.56$ & 7 \\
\hline & \multicolumn{4}{|c|}{ Mobile sperm (\%) } & \multicolumn{4}{|c|}{ Sperm longevity (sec) } \\
\hline & wild & & farmed & & wild & & farmed & \\
\hline & mean \pm SD & $\mathrm{N}$ & mean \pm SD & $\mathrm{N}$ & mean \pm SD & $\mathrm{N}$ & mean \pm SD & $\mathrm{N}$ \\
\hline \multicolumn{9}{|l|}{ week } \\
\hline $\begin{array}{l}13 \\
14\end{array}$ & $\begin{array}{l}35.60 \pm 27.59 \\
56.00 \pm 14.56\end{array}$ & $\begin{array}{l}5 \\
6\end{array}$ & $\begin{array}{l}36.5 / \pm 16.65 \\
55.71 \pm 18.43\end{array}$ & 7 & $\begin{array}{c}293.63 \pm 246.59 \\
213.03 \pm 62.67\end{array}$ & $\begin{array}{l}5 \\
6\end{array}$ & $\begin{array}{l}1 / 4.64 \pm 58.32 \\
229.05 \pm 35.49\end{array}$ & 7 \\
\hline 15 & $65.50 \pm 17.74$ & 6 & $52.71 \pm 11.03$ & 7 & $233.11 \pm 31.87$ & 6 & $178.38 \pm 35.30$ & 7 \\
\hline 16 & $63.33 \pm 10.07$ & 6 & $68.57 \pm 17.90$ & 7 & $308.78 \pm 63.13$ & 6 & $291.00 \pm 84.52$ & 7 \\
\hline 17 & $67.83 \pm 6.76$ & 6 & 55.71 v 19.86 & 7 & $261.17 \pm 46.15$ & 6 & $196.24 \pm 49.95$ & 7 \\
\hline
\end{tabular}


Table S2. Descriptive statistics (mean \pm SD) and number of samples analysed in each experimental week, for both wild caught and farmed males, for the \% of saturated fatty acids (SFA), unsaturated fatty acids (UFA), monosaturated fatty acids (MUFA), polysaturated fatty acids (PUFA), omega-3 and omega-6 in sperm.

\begin{tabular}{|c|c|c|c|c|c|c|c|c|}
\hline & \multicolumn{8}{|c|}{ Sperm fatty acid content (\%) } \\
\hline & \multicolumn{4}{|c|}{ SFA } & \multicolumn{4}{|c|}{ UFA } \\
\hline & \multirow{2}{*}{$\begin{array}{c}\text { wild } \\
\text { mean } \pm \text { SD }\end{array}$} & & \multicolumn{2}{|l|}{ farmed } & \multirow{2}{*}{$\begin{array}{c}\text { wild } \\
\text { mean } \pm \text { SD }\end{array}$} & \multicolumn{3}{|c|}{ farmed } \\
\hline & & $\mathrm{N}$ & mean \pm SD & $\mathrm{N}$ & & $\mathrm{N}$ & mean \pm SD & $\mathrm{N}$ \\
\hline week & & & & & & & & \\
\hline 13 & $26.10 \pm 0.84$ & 5 & $28.95 \pm 3.95$ & 6 & $70.46 \pm 0.97$ & 5 & $67.17 \pm 3.96$ & 6 \\
\hline 14 & $25.77 \pm 1.25$ & 5 & $27.71 \pm 1.33$ & 6 & $70.40 \pm 1.34$ & 5 & $68.18 \pm 1.22$ & 6 \\
\hline 15 & $26.19 \pm 1.41$ & 6 & $26.84 \pm 1.11$ & 7 & $70.29 \pm 1.33$ & 6 & $68.78 \pm 0.94$ & 7 \\
\hline 16 & $26.21 \pm 1.12$ & 5 & $26.47 \pm 0.56$ & 6 & $69.98 \pm 1.61$ & 5 & $69.17 \pm 0.45$ & 6 \\
\hline \multirow[t]{4}{*}{17} & $27.09 \pm 0.80$ & 6 & $27.05 \pm 0.83$ & 6 & $69.78 \pm 1.30$ & 6 & $69.07 \pm 1.41$ & 6 \\
\hline & \multicolumn{4}{|c|}{ MUFA } & \multicolumn{4}{|c|}{ PUFA } \\
\hline & wild & & farmed & & wild & & farmed & \\
\hline & mean \pm SD & $\mathrm{N}$ & mean \pm SD & $\mathrm{N}$ & mean \pm SD & $\mathrm{N}$ & mean \pm SD & $\mathrm{N}$ \\
\hline \multicolumn{9}{|l|}{ week } \\
\hline 13 & $23.02 \pm 1.18$ & 5 & $21.06 \pm 1.20$ & 6 & $47.44 \pm 1.61$ & 5 & $46.11 \pm 4.31$ & 6 \\
\hline 14 & $21.86 \pm 1.84$ & 5 & $20.44 \pm 1.27$ & 6 & $48.54 \pm 1.21$ & 5 & $47.74 \pm 0.63$ & 6 \\
\hline 15 & $22.02 \pm 1.66$ & 6 & $20.53 \pm 0.65$ & 7 & $48.27 \pm 1.60$ & 6 & $48.25 \pm 1.12$ & 7 \\
\hline 16 & $21.30 \pm 2.00$ & 5 & $20.24 \pm 0.67$ & 6 & $48.68 \pm 1.49$ & 5 & $48.93 \pm 0.98$ & 6 \\
\hline 17 & $21.45 \pm 2.01$ & 6 & $20.75 \pm 0.85$ & 6 & $48.33 \pm 1.22$ & 6 & $48.32 \pm 1.60$ & 6 \\
\hline & \multicolumn{4}{|c|}{ OMEGA 3} & \multicolumn{4}{|c|}{ OMEGA 6} \\
\hline & wild & & farmed & & wild & & farmed & \\
\hline & mean \pm SD & $\mathrm{N}$ & mean \pm SD & $\mathrm{N}$ & mean \pm SD & $\mathrm{N}$ & mean \pm SD & $\mathrm{N}$ \\
\hline \multicolumn{9}{|l|}{ week } \\
\hline 13 & $25.53 \pm 1.48$ & 5 & $33.28 \pm 3.74$ & 6 & $19.75 \pm 1.75$ & 5 & $10.46 \pm 0.91$ & 6 \\
\hline 14 & $27.09 \pm 2.05$ & 5 & $30.24 \pm 7.49$ & 6 & $18.85 \pm 2.32$ & 5 & $10.68 \pm 0.67$ & 6 \\
\hline 15 & $24.75 \pm 5.27$ & 6 & $32.96 \pm 5.12$ & 7 & $19.42 \pm 2.48$ & 6 & $10.96 \pm 0.79$ & 7 \\
\hline 16 & $26.73 \pm 2.16$ & 5 & $35.10 \pm 0.40$ & 6 & $19.05 \pm 2.35$ & 5 & $11.27 \pm 0.61$ & 6 \\
\hline 17 & $26.27 \pm 2.55$ & 6 & $34.69 \pm 0.98$ & 6 & $19.54 \pm 2.30$ & 6 & $11.46 \pm 0.72$ & 6 \\
\hline
\end{tabular}

